\title{
Comparison of short-term outcomes of robotic-assisted and laparoscopic-assisted D2 gastrectomy for gastric cancer: a meta-analysis
}

\author{
Xinsheng Zhang ${ }^{1}$, Weibin Zhang ${ }^{2}$, Zhen Feng ${ }^{1}$, Zhiwei Sun ${ }^{1}$, Qianshi Zhang ${ }^{1}$, Shuangyi Ren ${ }^{1}$ \\ ${ }^{1}$ Department of General Surgery, The Second Affiliated Hospital of Dalian Medical University, Dalian, Liaoning Province, China \\ ${ }^{2}$ Department of General Surgery, Jinzhou Central Hospital, Jinzhou City, Liaoning Province, China
}

Videosurgery Miniinv 2021; 16 (3): 443-454

DOI: https://doi.org/10.5114/wiitm.2021.105731

\begin{abstract}
Aim: The aim of the study was to compare the outcomes of robot-assisted (RAGD2) and laparoscopy-assisted gastrectomy with D2 lymphadenectomy (LAGD2) for patients with gastric cancer.

Material and methods: Relevant articles published up to September 2020 were searched. The weighted mean difference (WMD) was used to pool continuous variables, while risk ratio (RR) was calculated for dichotomous outcomes. Results: RAGD2 required a longer operating time (WMD $=29.78,95 \%$ confidence interval (CI): 15.97-43.59) and had less operative blood loss (WMD $=-31.93,95 \%$ Cl: -44.03 to -19.83$)$, shorter time to first flatus (WMD $=-0.13$, $95 \% \mathrm{Cl}:-0.22$ to -0.04$)$, shorter time to liquid diet (WMD $=-0.20,95 \% \mathrm{Cl}:-0.28$ to 0.12$)$, and fewer severe complications $(R R=0.62,95 \% \mathrm{Cl}: 0.43-0.90)$ and overall complications ( $R R=0.75,95 \% \mathrm{Cl}: 0.62-0.91)$ than LAGD2.

Conclusions: RAGD2 could be beneficial in reducing operative blood loss and postoperative complications relative to LAGD2.
\end{abstract}

Key words: robot-assisted gastrectomy, laparoscopy-assisted gastrectomy, meta-analysis.

\section{Introduction}

Gastric cancer is one of the most common causes of cancer-related death affecting 13.5/100,000 people worldwide. The incidence of the disease varies widely between different areas, having the highest prevalence in East Asian countries [1]. Gastric cancer in China accounts for $42.5 \%$ of the global incidence and $45.0 \%$ of deaths [2]. In recent years, the worldwide incidence of gastric cancer has been decreasing, but it remains a serious health problem worldwide.

Currently, surgery is recommended as the primary treatment for patients with gastric cancer. Compared with conventional open surgery, laparoscopic surgery has been shown to have many advantages, such as mitigation of postoperative pain, early recovery of gastrointestinal function, and early return to normal activity [3, 4]. For surgeons, two-dimensional (2D) laparoscopy limits depth perception, which increases strain when working in a three-dimensional space. Three-dimensional (3D) laparoscopy has been introduced [5]. Meanwhile, the technology is limited when completion of lymph node dissection occurred. Although laparoscopic gastrectomy has been widely accepted as a treatment for early gastric cancer, the application of laparoscopic D2 lymphadenectomy remains controversial [6]. Recently, robotic systems have been developed [7, 8]. Multiple retrospective studies comparing 2D laparoscopy with 3D laparos- 
copy and robotic surgery have been published. However, most outcome indicators remain controversial, such as operation time, postoperative hospital stay, and postoperative complications. For example, Lee et al. reported that robotic surgery may be related to less blood loss than conventional laparoscopic surgery in gastric cancer patients [9]. Nevertheless, the study reported by Cui et al. [10] showed that laparoscopy-assisted gastrectomy with D2 lymphadenectomy (LAGD2) presented more harvested lymph nodes, shorter postoperative hospital stay, and lower operative cost than robot-assisted gastrectomy with D2 lymphadenectomy (RAGD2). Accordingly, it is necessary to synthesize the latest research results through meta-analysis to assess surgical outcomes after RAGD2 and LAGD2.

\section{Aim}

This meta-analysis was performed to compare the clinical efficacy and postoperative complications of RAGD2 versus LAGD2 for gastric cancer. Based on the pooled data, we demonstrated that RAGD2 could be beneficial in reducing operative blood loss and postoperative complications relative to LAGD2.

\section{Material and methods}

\section{Selection strategy}

The meta-analysis was performed based on the Preferred Reporting Items for Systematic Reviews and Meta-analyses (PRISMA) guidelines [11]. The eligible studies were identified by searching databases including PubMed, Embase, Cochrane Library, CNKI, Wanfang, and CQVIP for studies published up to September 1,2020 . The combination of the following terms was used: "robot”, "robotic", "laparoscopic", "laparoscope”, "laparoscopy”, "gastric carcinoma”, "stomach carcinoma”, "gastric cancer”, "stomach cancer”, "gas tric tumor", "stomach tumor”, "gastric neoplasms", "stomach neoplasms", "D2", and "extended lymphadenectomy". The enrolled studies were selected without any language limitations. Moreover, print-out literature was searched through manual retrieval, and the references of the included articles were further checked to identify more relevant papers.

\section{Study selection}

Randomized controlled trials (RCTs), non-randomized clinical studies, and cohort studies were included in this meta-analysis if (1) the study investigated the short-term outcomes of RAGD2 versus LAGD2 (lymphatic dissection, including total gastrectomy, distal gastrectomy, and proximal gastrectomy); (2) gastric cancer was diagnosed by gastroscopy or pathology, and the patients had not received preoperative radiotherapy and/or chemotherapy; and (3) the article reported at least one short-term outcome, such as surgery-related outcomes or postoperative complications.

Studies were excluded if: (1) the study included patients who underwent D2, D1 $+\alpha / \beta$ gastrectomy, or there were no independent data for D2; (2) the study only included subjects who underwent RAGD2 or LAGD2; and (3) the study included incomplete data or the full text could not be obtained. Furthermore, if duplicate data were found, we only included the study that provided more detailed information.

\section{Data extraction and quality assessment}

Two investigators independently extracted the following information: the name of the first author, year of publication, baseline characteristics of included subjects (such as sample size, type of research, age, sex, body mass index (BMI), and TNM stage), and outcome data. If disagreements occurred during data extraction and quality assessment, the two investigators would discuss the matter until they reached an agreement.

The quality of RCTs was assessed based on the Cochrane Collaboration's tool [12], and the methodological quality of the cohort studies was evaluated using the Newcastle-Ottawa scale (NOS) [13]. The NOS includes nine items with scales ranging from 0 to 9 , with 7-9 indicating high quality, 4-6 scores indicating intermediate quality, and $<4$ indicating low quality.

\section{Statistical analysis}

Continuous variables included operating time, operative blood loss, number of retrieved lymph nodes, time to first flatus, time to liquid diet, and postoperative length of stay. These data were pooled using the weighted mean difference (WMD) with a 95\% confidence interval $(\mathrm{Cl})$. The outcomes of categorical variables such as postoperative complications and death were meta-analyzed using the risk ratio (RR) and $95 \% \mathrm{Cl}$. Heterogeneity was calculated based on Cochran's Q and $I^{2}$ tests [14]. Significant heterogeneity was defined among the included studies when $p<0.05$ and/or $l^{2}>50 \%$; in such cases, the random 
effects model was used. Otherwise, the fixed-effects model was selected ( $p>0.05, R^{2}<50 \%$ ). Furthermore, the sensitivity of the results was calculated by omitting one study each time. The Egger test was used to assess potential publication bias. All statistical analyses were conducted using RevMan 5.3 (The Cochrane Collaboration, Oxford, UK) and Stata 11.0 (StataCorp LP, College Station, Texas, USA).

\section{Results}

\section{Literature search}

Figure 1 shows a detailed flowchart of the literature selection. A total of 79, 105, 7, 33, 42, and 7 articles were retrieved from the PubMed, Embase, Cochrane Library, CNKI, Wanfang, and CQVIP databases, respectively. After removing duplicate articles, 194 remained. We then reviewed the titles and abstracts, and 173 articles were eliminated. After reading the full text, nine of the remaining 21 articles were excluded. Manual searches failed to find studies that could be included in the analysis. Finally, 12 articles were included in this meta-analysis [9, 10, 15-24].

\section{Characteristics of the enrolled studies}

As shown in Table I, 3176 subjects (1339 patients in the RAGD2 group and 1837 patients in the LAGD2 group) were included in this meta-analysis. All included studies were retrospective cohort studies published between 2010 and 2020. These studies were conducted in China, South Korea, and Italy. The included sample sizes ranged from 70 to 570 . The average age of the study subjects was 53.6-71 years old. Except for the study by Lee et al. [9], no significant difference in age was found between the two groups in the remaining studies. In addition, similar baseline information, such as BMI, ASA grade, tumor size, and TNM staging, in the two groups were reported in each article. All included studies had an NOS score of 5-8, and the methodological quality was medium or high.

\section{Results of meta-analysis}

\section{Clinical efficacy}

Six variables were analyzed: operating time, operative blood loss, number of retrieved lymph nodes, time to first flatus, time to liquid diet, and postoperative length of stay. Obvious heterogeneity occurred among the included studies for the above indicators

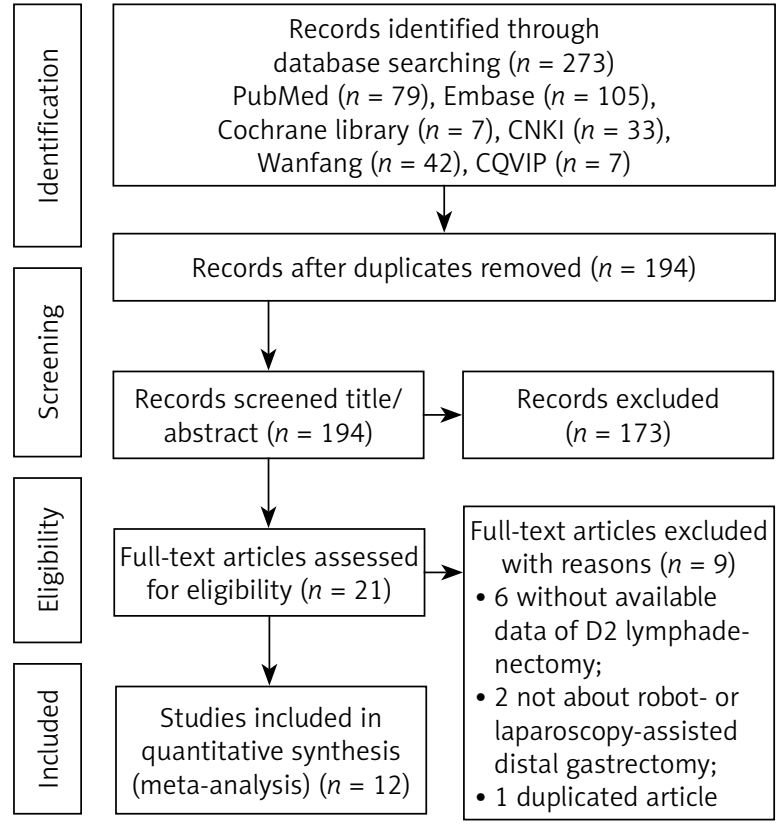

Figure 1. Flow chart of literature screening. Relevant literature in the PubMed, Embase, Cochrane library, CNKI, Wanfang, and CQVIP databases was identified using the designated search terms. After screening the titles, abstracts, and full texts, 12 eligible studies were finally included in this meta-analysis

( $p<0.05, R^{2}>50 \%$ ); therefore, the random effects model was selected.

In total, 12 studies reported data on operating time, and the results showed that RAGD2 was significantly longer than LAGD2 $(\mathrm{WMD}=29.78 \mathrm{~min}$, 95\% Cl: 15.97-43.59; $p<0.0001$, Figure 2 A). Except for the study by Cui et al. [10], all studies reported a difference in operating blood loss between the two groups. The pooled data showed that the operating blood loss for RAGD2 was significantly less than that for LAGD2 (WMD = -31.93 $\mathrm{ml}, 95 \% \mathrm{Cl}$ : -44.03 to $-19.83 ; p<0.00001$, Figure $2 \mathrm{~B}$ ).

In total, 11 articles [3, 10, 15-18, 20-24] reported the difference in the number of retrieved lymph nodes, and the combined results indicated that the difference between the two groups was not statistically significant $(\mathrm{WMD}=1.65,95 \% \mathrm{Cl}:-0.14$ to 3.44 ; $p=0.07$, Figure 2 C). Eight [10, 16-19, 21, 23, 24] and seven studies $[15,16,18-20,23,24]$ reported the difference in time to first flatus and time to liquid diet, respectively. The results showed that time to first flatus (WMD $=-0.13$ days, $95 \% \mathrm{Cl}:-0.22$ to $-0.04 ; p=0.005$, Figure $2 \mathrm{D}$ ) and time to liquid 
Table I. Characteristics of 12 studies included in this meta-analysis

\begin{tabular}{|c|c|c|c|c|c|c|c|c|c|c|}
\hline $\begin{array}{l}\text { Study } \\
\text { (country) }\end{array}$ & Duration & Groups & $N$ & $M / F$ & $\begin{array}{c}\text { Age } \\
\text { [years] }\end{array}$ & $\begin{array}{c}\mathrm{BMI} \\
{\left[\mathrm{kg} / \mathrm{m}^{2}\right]}\end{array}$ & $\begin{array}{l}\text { ASA, } \\
\text { I/II/III }\end{array}$ & $\begin{array}{c}\text { Tumor size } \\
{[\mathrm{cm}]}\end{array}$ & $\begin{array}{c}\text { TNM stage, } \\
\text { I/II/III }\end{array}$ & $\begin{array}{l}\text { Type of } \\
\text { resection }\end{array}$ \\
\hline \multirow{2}{*}{$\begin{array}{l}\text { Cui, H } \\
2020 \\
\text { (China) }\end{array}$} & \multirow{2}{*}{$\begin{array}{c}2016.01- \\
2019.12\end{array}$} & RAG & 187 & $122 / 65$ & $59.0 \pm 10.5$ & $24.1 \pm 3.0$ & $4 / 162 / 21$ & $3.5 \pm 2.4$ & $81 / 47 / 59$ & \multirow{2}{*}{$\begin{array}{c}\text { Distal } \\
\text { gastrec- } \\
\text { tomy }\end{array}$} \\
\hline & & LAG & 344 & $250 / 94$ & $57.2 \pm 11.9$ & $23.8 \pm 3.4$ & $5 / 304 / 35$ & $3.3 \pm 2.0$ & $151 / 89 / 104$ & \\
\hline \multirow{2}{*}{$\begin{array}{l}\text { Hu, SD } \\
2017 \\
\text { (China) }\end{array}$} & \multirow{2}{*}{$\begin{array}{l}2014.12- \\
2016.06\end{array}$} & RAG & 39 & 28/11 & $59.41 \pm 12.34$ & $N R$ & $N R$ & $N R$ & 7/13/19 & \multirow[t]{2}{*}{ NR } \\
\hline & & LAG & 39 & 20/19 & $56.72 \pm 12.47$ & $N R$ & $N R$ & $N R$ & $10 / 7 / 22$ & \\
\hline \multirow{2}{*}{$\begin{array}{l}\text { Lee, J } 2015 \\
\text { (Korea) }\end{array}$} & \multirow{2}{*}{$\begin{array}{l}2003- \\
2010\end{array}$} & RAG & 133 & $85 / 48$ & $53.6 \pm 13.2$ & $23.2 \pm 2.7$ & NR & NR & $101 / 15 / 17$ & \multirow{2}{*}{$\begin{array}{c}\text { Distal } \\
\text { gastrec- } \\
\text { tomy }\end{array}$} \\
\hline & & LAG & 267 & $154 / 113$ & $59.2 \pm 11.7^{*}$ & $23.7 \pm 2.8$ & $N R$ & $N R$ & 218/32/17 & \\
\hline \multirow{2}{*}{$\begin{array}{l}\text { Li, SY } 2018 \\
\text { (China) }\end{array}$} & \multirow{2}{*}{$\begin{array}{c}2015.05- \\
2017.05\end{array}$} & RAG & 50 & $35 / 15$ & $65.6 \pm 8.3$ & $24.3 \pm 2.1$ & NR & NR & NR & \multirow{2}{*}{$\begin{array}{c}\text { Distal } \\
\text { gastrec- } \\
\text { tomy }\end{array}$} \\
\hline & & LAG & 56 & $39 / 17$ & $66.0 \pm 7.4$ & $24.6 \pm 2.4$ & $N R$ & NR & $N R$ & \\
\hline \multirow{2}{*}{$\begin{array}{l}\text { Liu, ZL } \\
2020 \\
\text { (China) }\end{array}$} & \multirow{2}{*}{$\begin{array}{c}2014.10- \\
2018.08\end{array}$} & RAG & 108 & \multirow[t]{2}{*}{$262 / 109$} & \multirow[t]{2}{*}{$61 \pm 4$} & \multirow[t]{2}{*}{$23.0 \pm 2.1$} & \multirow[t]{2}{*}{$N R$} & \multirow[t]{2}{*}{ NR } & \multirow[t]{2}{*}{$60 / 99 / 212$} & \multirow[t]{2}{*}{ NR } \\
\hline & & LAG & 263 & & & & & & & \\
\hline \multirow{2}{*}{$\begin{array}{l}\text { Pugliese, R } \\
2010 \text { (Italy) }\end{array}$} & \multirow{2}{*}{$\begin{array}{c}2000.06- \\
2009.10\end{array}$} & RAG & 18 & 7/11 & $65.7(45-82)$ & \multirow[t]{2}{*}{$28.8(21-40)$} & \multirow[t]{2}{*}{$7 / 42 / 21$} & \multirow[t]{2}{*}{$2.2 \pm 0.8$} & \multirow[t]{2}{*}{$50 / 8 / 9 / 3$} & \multirow{2}{*}{$\begin{array}{l}\text { Distal } \\
\text { gastrec- } \\
\text { tomy }\end{array}$} \\
\hline & & LAG & 52 & $36 / 16$ & $71(41-86)$ & & & & & \\
\hline \multirow{2}{*}{$\begin{array}{l}\text { Shen, } \\
\text { XQ } 2018 \\
\text { (China) }\end{array}$} & \multirow{2}{*}{$\begin{array}{c}2016.09- \\
2017.09\end{array}$} & RAG & 65 & $49 / 16$ & $58 \pm 10$ & $22.9 \pm 2.6$ & $12 / 42 / 11$ & NR & 9/19/37 & \multirow{2}{*}{$\begin{array}{c}\text { Distal } \\
\text { or total } \\
\text { gastrec- } \\
\text { tomy }\end{array}$} \\
\hline & & LAG & 97 & $67 / 30$ & $59 \pm 10$ & $22.4 \pm 2.9$ & $15 / 66 / 16$ & $N R$ & $14 / 22 / 61$ & \\
\hline Wang, & 2016.01- & RAG & 223 & $183 / 40$ & $57.7 \pm 10.9$ & $22.1 \pm 3.5$ & $115 / 77 / 31$ & $5.0 \pm 1.9$ & $53 / 83 / 87$ & Distal \\
\hline $\begin{array}{l}\text { WJ } 2019 \\
\text { (China) }\end{array}$ & & LAG & 223 & $180 / 43$ & $57.4 \pm 11.1$ & $22.2 \pm 3.4$ & $112 / 79 / 32$ & $5.1 \pm 2.2$ & $54 / 84 / 85$ & $\begin{array}{c}\text { or total } \\
\text { gastrec- } \\
\text { tomy }\end{array}$ \\
\hline Xue, YG & 2012.02- & RAG & 35 & $26 / 9$ & $59.2 \pm 9.6$ & $24.6 \pm 2.9$ & NR & $4.5 \pm 1.8$ & $6 / 8 / 21$ & Distal \\
\hline $\begin{array}{l}2016 \\
\text { (China) }\end{array}$ & & LAG & 35 & $25 / 10$ & $56.2 \pm 14.1$ & $23.4 \pm 2.3$ & NR & $4.2 \pm 1.9$ & 5/13/17 & $\begin{array}{c}\text { gastrec- } \\
\text { tomy }\end{array}$ \\
\hline $\begin{array}{l}\text { Ye, SP } 2019 \\
\text { (China) }\end{array}$ & $\begin{array}{c}2015.06- \\
2018.10\end{array}$ & RAG & 99 & $58 / 41$ & $58.7 \pm 6.7$ & $\begin{array}{c}23.9 \\
(17.3-28.6) \\
\end{array}$ & $52 / 40 / 7$ & $4.76 \pm 1.27$ & $2 / 54 / 43$ & $\begin{array}{c}\text { Total } \\
\text { gastrec- }\end{array}$ \\
\hline & & LAG & 106 & $55 / 51$ & $59.0 \pm 7.3$ & $\begin{array}{c}23.9 \\
(19.9-28.3)\end{array}$ & $53 / 44 / 9$ & $4.70 \pm 1.24$ & $3 / 51 / 52$ & \\
\hline Ye, SP & 2014.12- & RAG & 285 & $189 / 96$ & $57.1 \pm 8.3$ & $24.4 \pm 2.3$ & $168 / 102 / 15$ & $4.84 \pm 1.31$ & 7/149/129 & Distal \\
\hline $\begin{array}{l}2020 \\
\text { (China) }\end{array}$ & & LAG & 285 & $186 / 99$ & $57.0 \pm 8.6$ & $24.5 \pm 2.2$ & $161 / 111 / 13$ & $4.86 \pm 1.31$ & $4 / 146 / 135$ & $\begin{array}{c}\text { gastrec- } \\
\text { tomy }\end{array}$ \\
\hline Zhang, & 2009.01- & RAG & 97 & $66 / 31$ & $56.1 \pm 5.8$ & $22.5 \pm 3.6$ & NR & NR & $23 / 22 / 52$ & Proximal, \\
\hline $\begin{array}{l}\text { XL } 2012 \\
\text { (China) }\end{array}$ & & LAG & 70 & $49 / 21$ & $54.8 \pm 4.9$ & $21.7 \pm 2.1$ & NR & NR & $8 / 17 / 45$ & $\begin{array}{l}\text { distal } \\
\text { or total } \\
\text { gastrec- } \\
\text { tomy }\end{array}$ \\
\hline
\end{tabular}

ASA - American Society of Anesthesiologists classification, BMI-body mass index, $M$ - male, $F$-female, NR - not reported. *Significant difference between two groups.

diet $(\mathrm{WMD}=-0.20$ days, $95 \% \mathrm{Cl}:-0.28$ to -0.12 ; $p<0.00001$, Figure $2 \mathrm{E}$ ) were significantly shorter for RAGD2 than for LAGD2. Furthermore, no significant difference was found in the postoperative length of stay between the two groups (WMD $=-0.21$ days, $95 \% \mathrm{Cl}:-0.88$ to $0.47 ; p=0.55$, Figure $2 \mathrm{~F}$ ). 
A

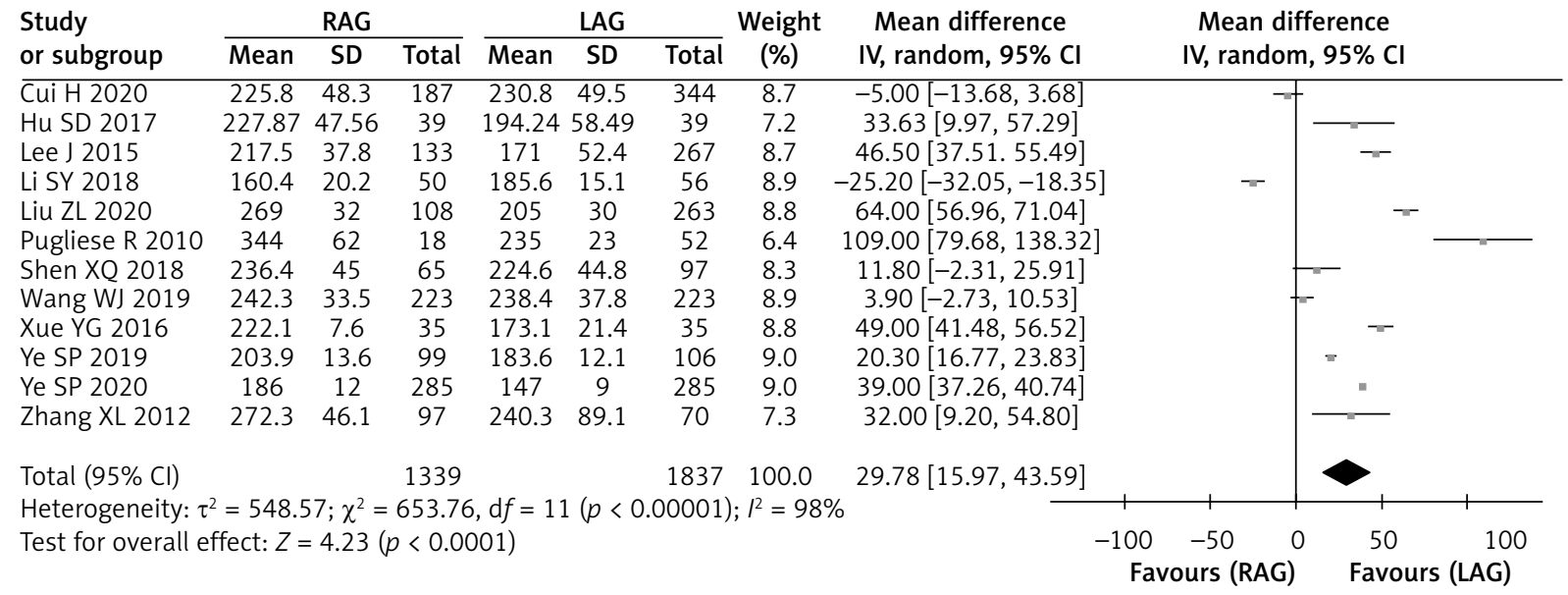

B

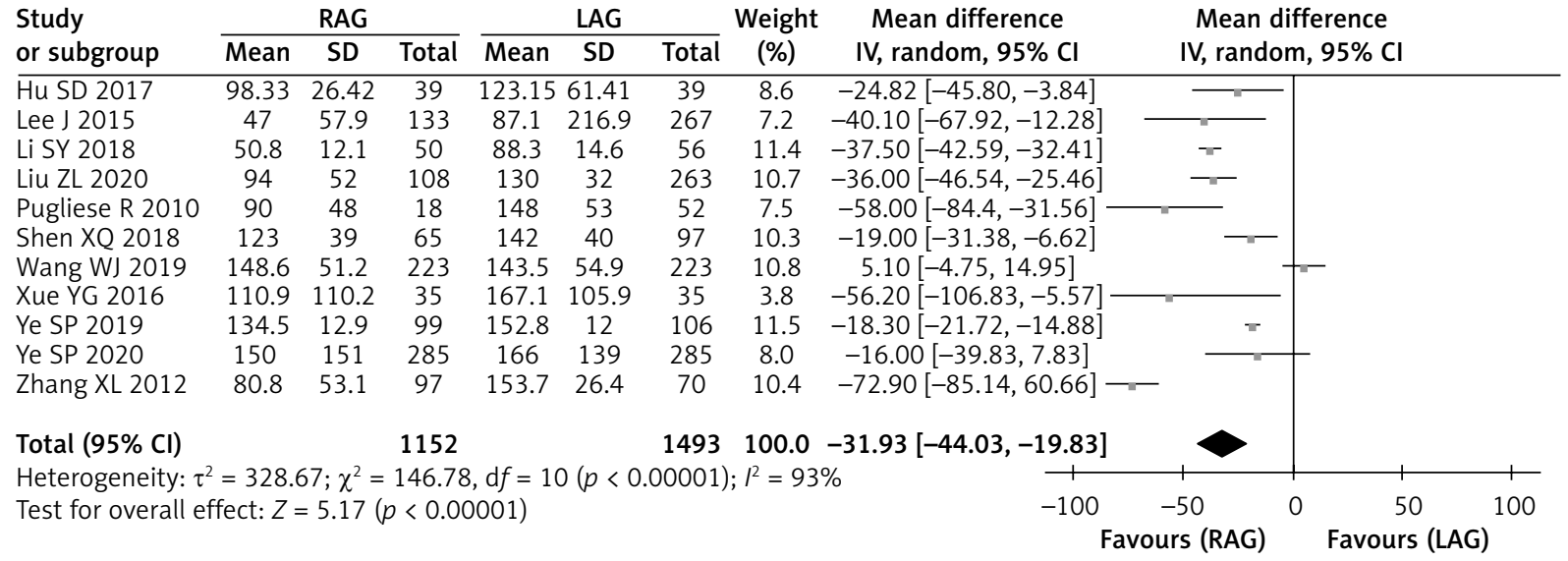

C

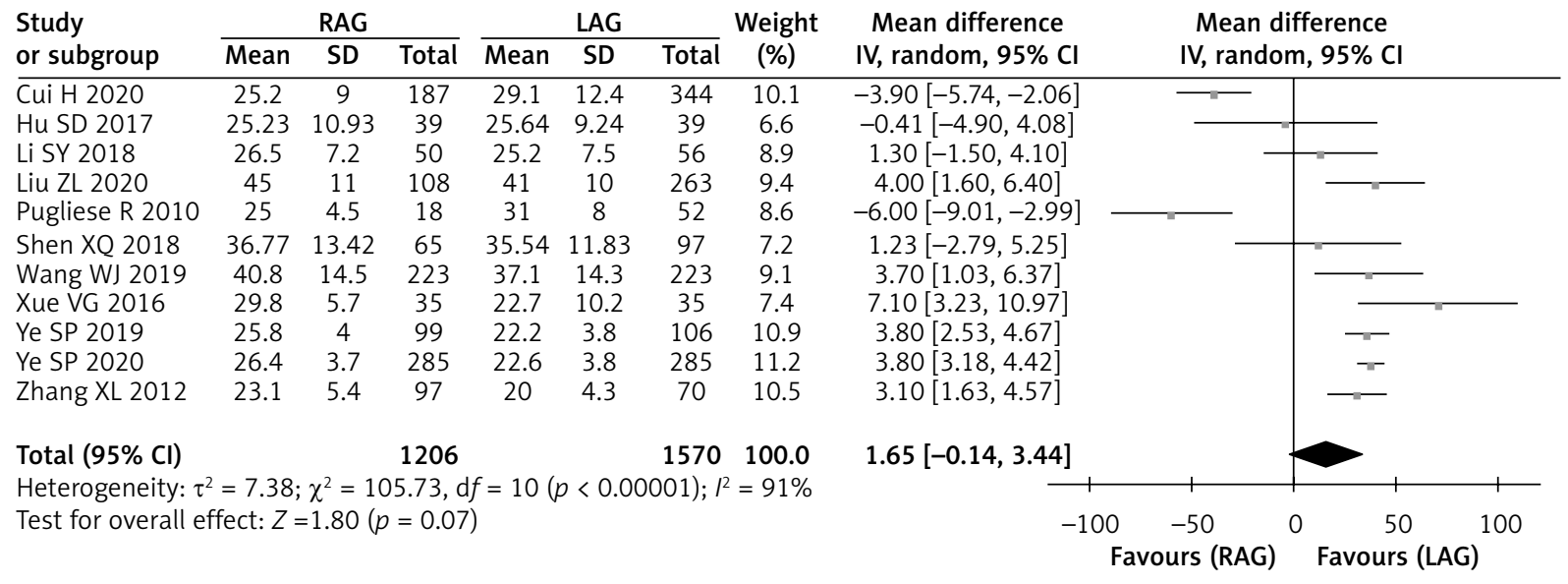

Figure 2. Forest plots for comparison of the clinical efficacy of RAGD2 and LAGD2. Operating time (A), operative blood loss (B), number of retrieved lymph nodes (C) 
D

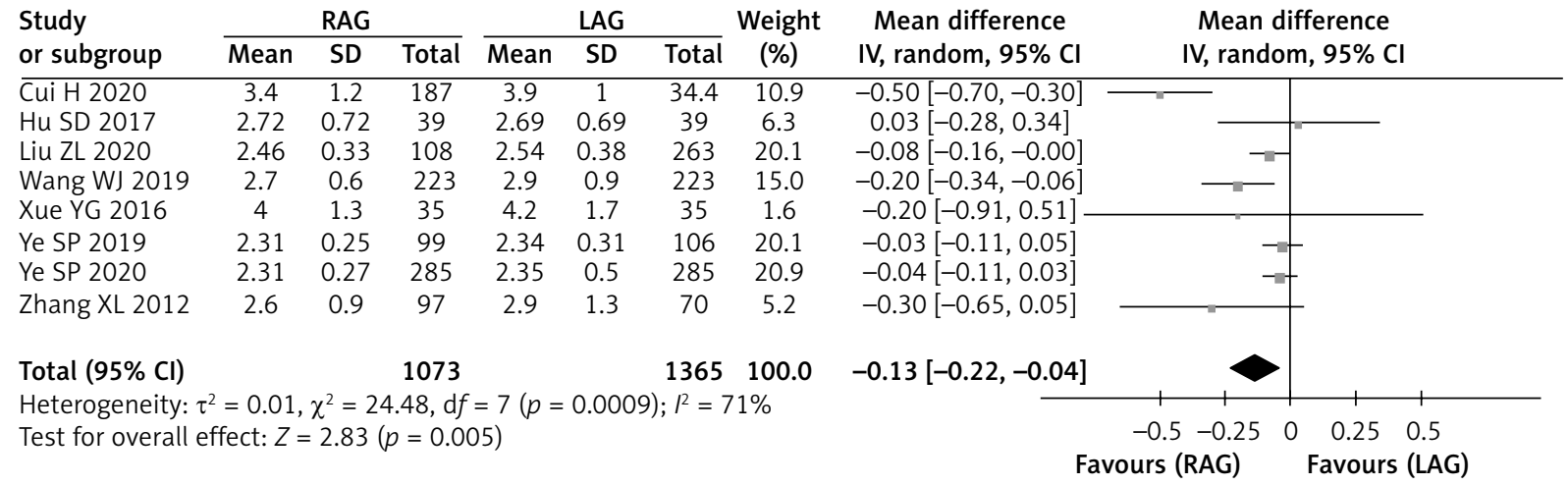

E

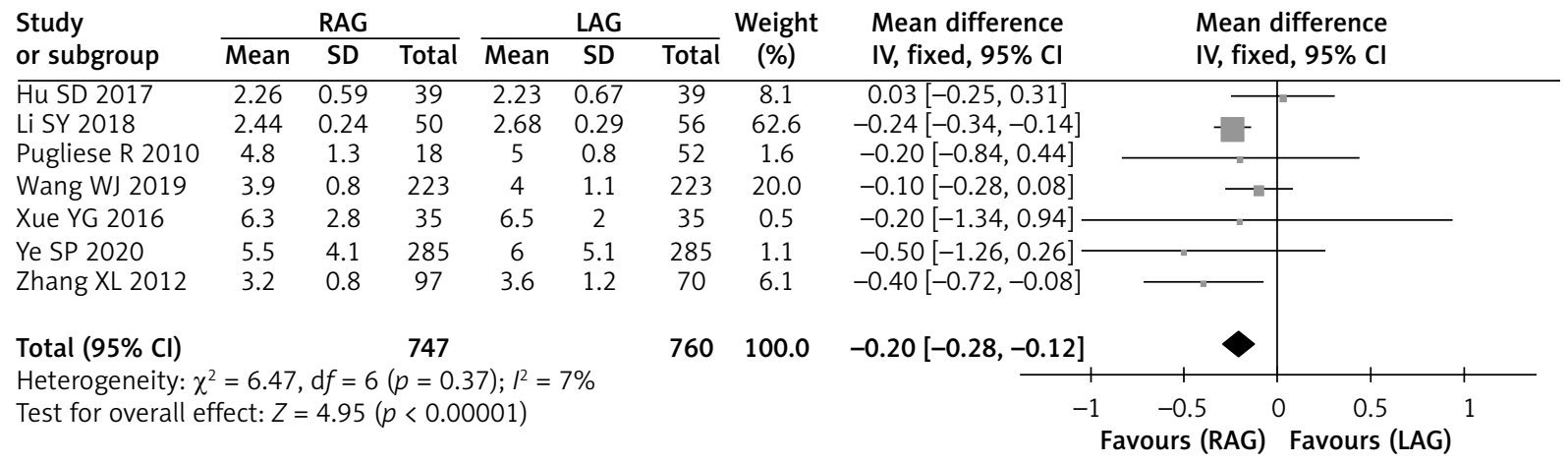

$\mathrm{F}$

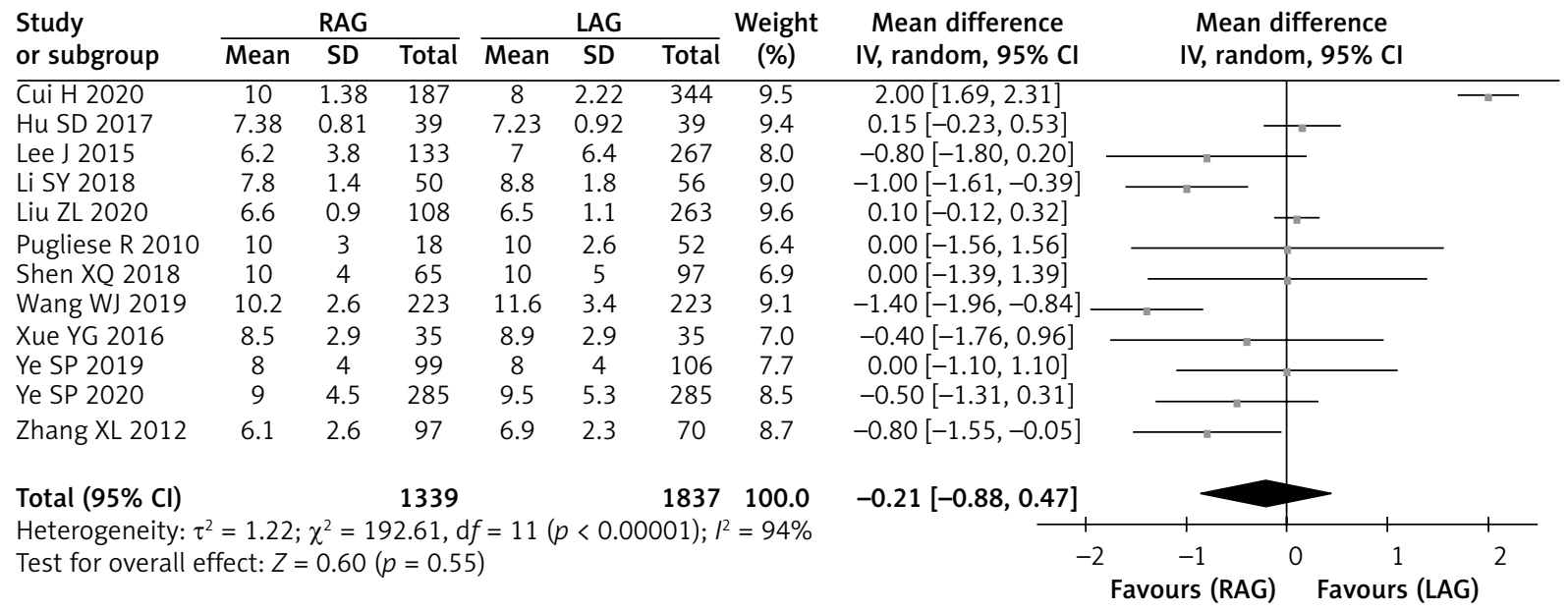

Figure 2. Cont. Time to first flatus (D), time to liquid diet (E), and postoperative length of stay (F)

\section{Postoperative complications}

No significant heterogeneity in postoperative complications among the included studies was observed between the RAGD2 and LAGD2 groups $\left(p>0.05, I^{2}<50 \%\right.$ ), and the fixed-effects model was used to pool effect values. The risks of wound infection $(\mathrm{RR}=0.74,95 \% \mathrm{Cl}: 0.42-1.30 ; p=0.29$, Figure $3 \mathrm{~A})$, intra-abdominal infection ( $R R=0.76,95 \% \mathrm{Cl}$ : 0.29-2.02; $p=0.58$, Figure $3 \mathrm{~B})$, pneumonia $(\mathrm{RR}=$ $0.84,95 \%$ Cl: $0.41-1.74 ; p=0.65$, Figure $3 \mathrm{C}$ ), intestinal obstruction $(\mathrm{RR}=0.70,95 \% \mathrm{Cl}: 0.27-1.87$; 
$p=0.48$, Figure $3 \mathrm{D})$, delayed gastric emptying $(\mathrm{RR}=1.14,95 \% \mathrm{Cl}: 0.47-2.75 ; p=0.78$, Figure $3 \mathrm{E})$, and anastomosis leakage ( $\mathrm{RR}=0.58,95 \% \mathrm{Cl}: 0.30$ $1.10 ; p=0.10$, Figure 3 F) was slightly lower in the RAGD2 group than in the LAGD2 group, but the difference was not statistically significant.

Five studies [10, 16, 18, 21, 22] reported severe complications, and nine studies [10, 16-18, 20-24] reported overall complications. Notably, severe com- plications, such as Clavien-Dindo classification $\geq$ III $(\mathrm{RR}=0.62,95 \% \mathrm{Cl}: 0.43-0.90 ; p=0.01$, Figure $3 \mathrm{G})$ and overall complications $(\mathrm{RR}=0.75,95 \% \mathrm{Cl}: 0.62-$ $0.91 ; p=0.003$, Figure $3 \mathrm{H}$ ) were significantly lower in the RAGD2 group than in the LAGD2 group.

In addition, the death rate was reported in five studies [15-17, 21, 23]. There was no significant heterogeneity between the studies ( $p=0.79, R^{2}=0 \%$ ). No significant difference in death rate was found

A

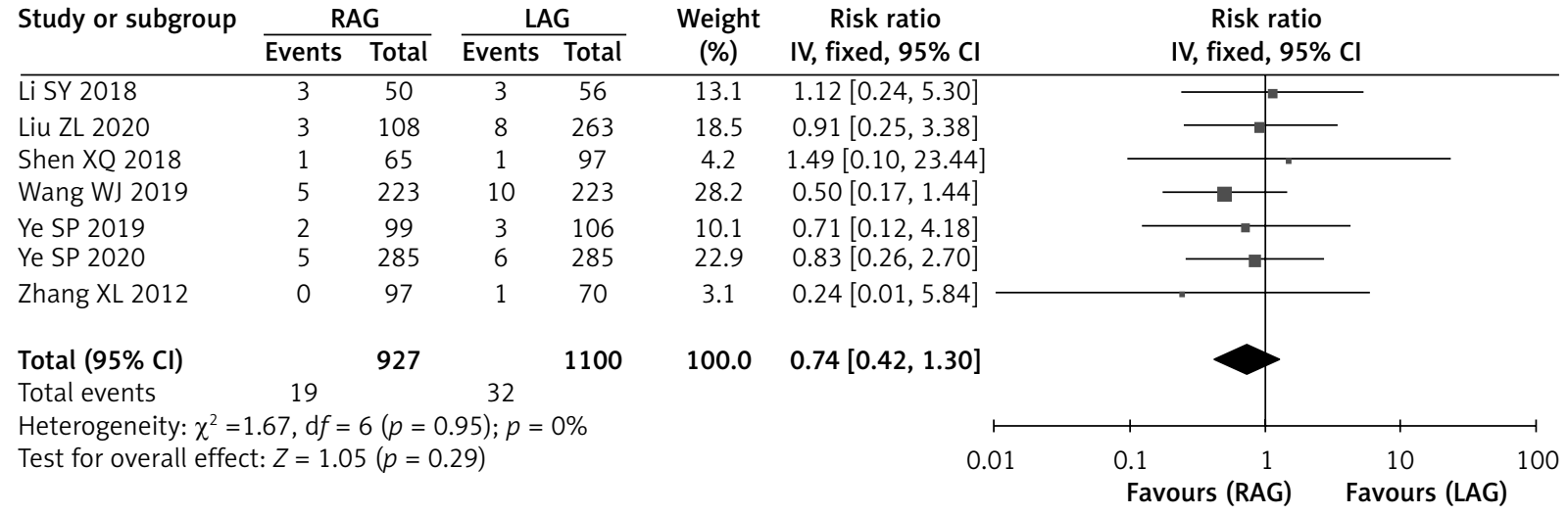

B

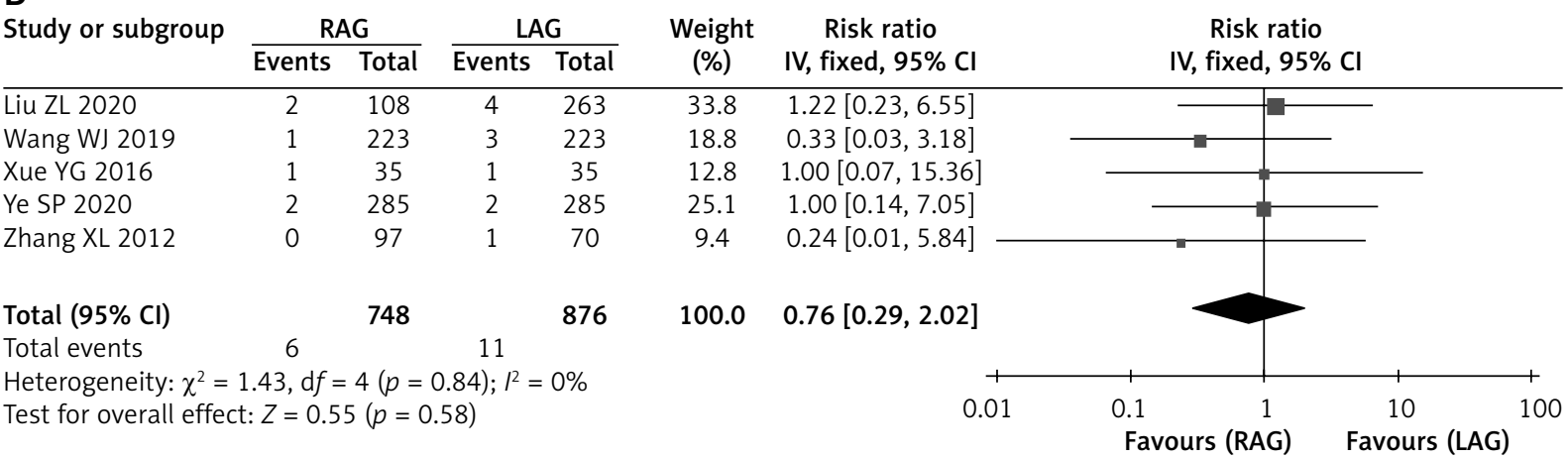

C

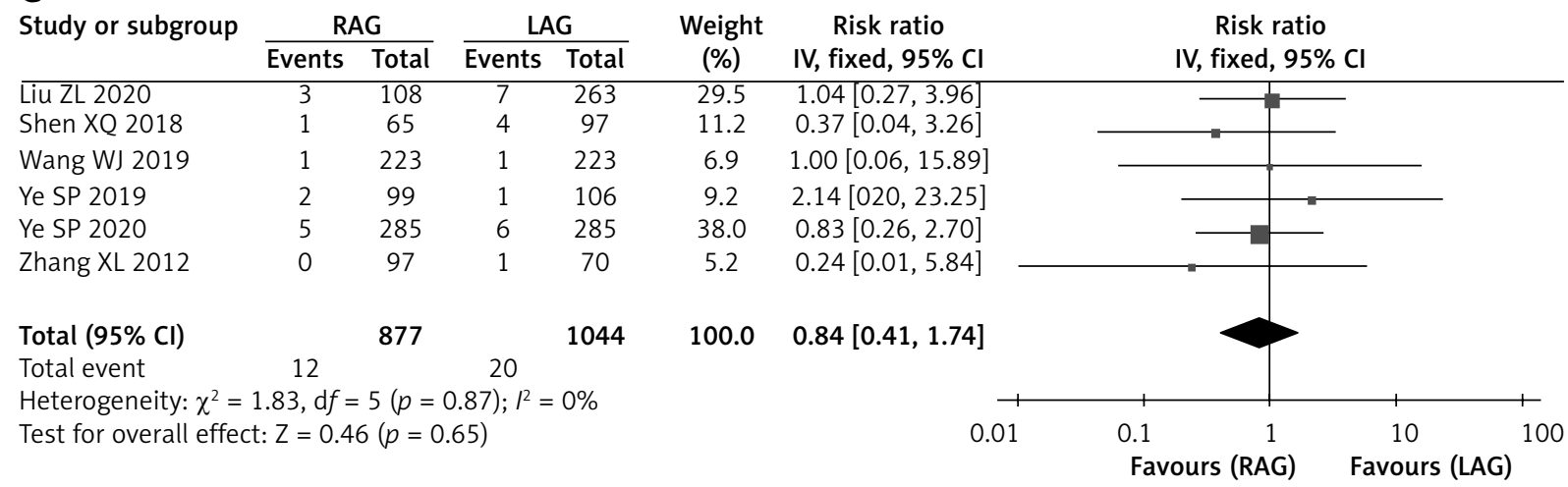

Figure 3. Forest plots for comparison of the postoperative complications between RAGD2 and LAGD2. Wound infection (A), intra-abdominal infection (B), pneumonia (C) 
$\mathrm{H}$

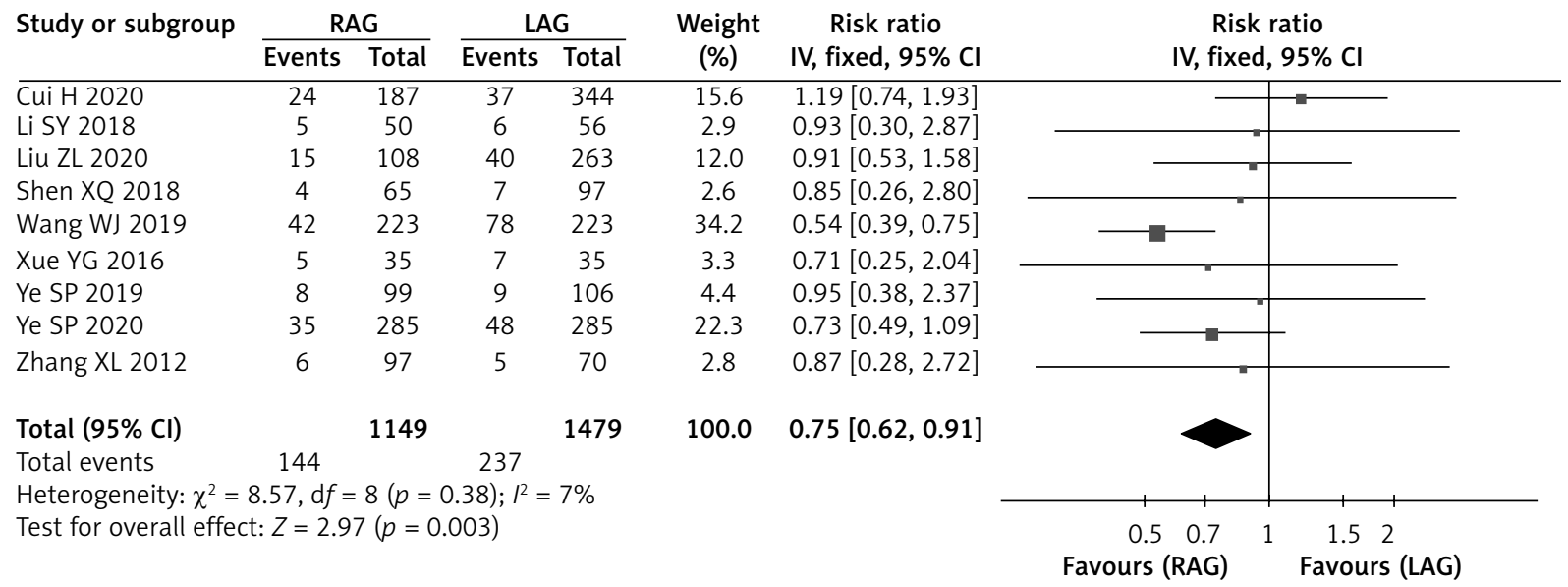

I

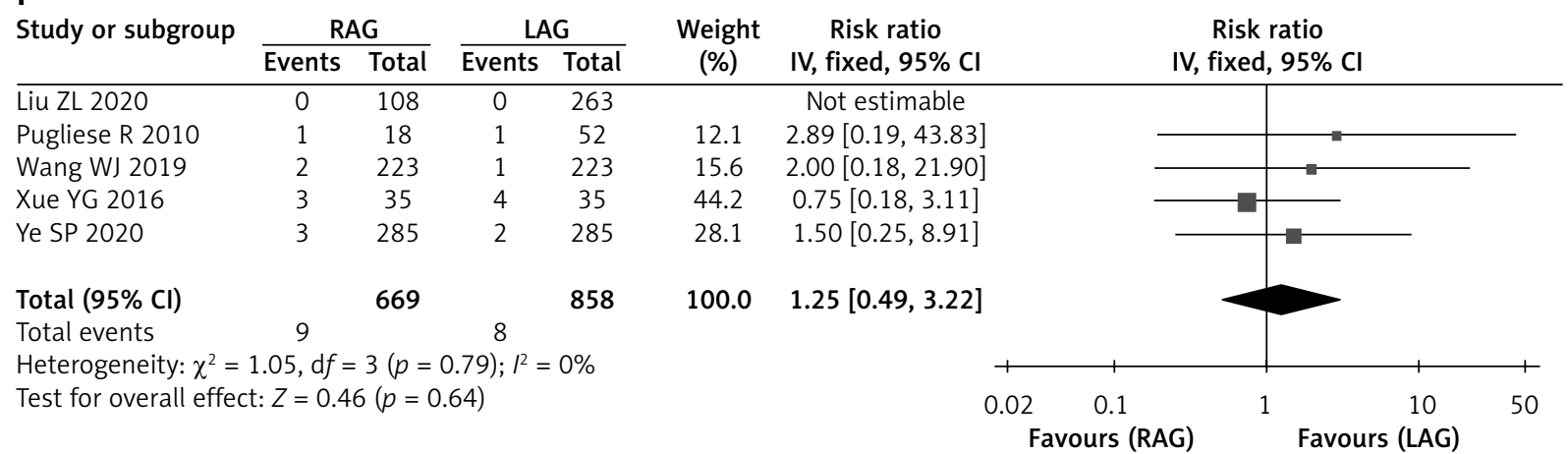

Figure 3. Cont. Overall complications $(\mathbf{H})$, and death rate (I)

between the RAGD2 and LAGD2 groups (RR $=1.25$, $95 \% \mathrm{Cl}: 0.49-3.22 ; p=0.64$, Figure $3 \mathrm{I}$ ).

\section{Publication bias and sensitivity analysis}

Table II shows that publication bias do not occur for all indicators $(p>0.05)$. Notably, after ignoring the studies of Cui et al. [10] or Pugliese et al. [15], the combined results of the number of retrieved lymph nodes became statistically significant $(p<0.05)$. Similarly, the combined results of postoperative length of stay also became statistically significant when we ignored the study of Cui et al. [10]. The difference between RAGD2 and LAGD2 with respect to severe complications and overall complications became non-significant when we omitted the study of Wang et al. [16].

\section{Discussion}

In recent years, minimally invasive surgery technology has developed rapidly in the field of gastroin- testinal surgery, and this technology has paved the way for improving the safety and accuracy of future operations [25]. Accordingly, the meta-analysis was designed to assess the efficacy of RAGD2 in comparison with LAGD2 in patients with gastric cancer. A total of 12 studies were included in the present meta-analysis. Compared with LAGD2, RAGD2 had a longer operating time, less operative blood loss, shorter time to first flatus and liquid diet, and fewer severe complications as well as overall complications. Similar efficacy was found in the two groups with respect to the number of retrieved lymph nodes, postoperative length of stay, and death rate. This meta-analysis demonstrated that RAGD2 might have good reproducibility and safety in gastric cancer patients, and this technology might be promoted in clinical practice.

Laparoscopic gastrectomy has been reported as an effective alternative to open surgery for the treatment of gastric cancer. Zheng et al. [26] confirmed 
Table II. Results of publication bias and sensitivity analysis

\begin{tabular}{|lcc|}
\hline Outcomes & Egger' s test, $P$-value & Sensitivity analyses, WMD/RR $(95 \% \mathrm{CI})$ \\
\hline Operative time & 0.479 & $24.33(10.28,38.38)$ to $34.50(22.83,46.18) \mathrm{min}$ \\
\hline Operative blood loss & 0.405 & $-31.93(-44.03,-19.83)$ to $-22.01(-32.98,-11.04) \mathrm{ml}$ \\
\hline Numbers of retrieved lymph nodes & 0.175 & $1.21(-0.64,3.07)$ to $2.38(0.96,3.80)^{\#}$ \\
\hline Time to first flatus & 0.162 & $-0.16(-0.28,-0.05)$ to $-0.07(-0.11,-0.02)$ days \\
\hline Time to liquid diet & 0.985 & $-0.23(-0.32,-0.14)$ to $-0.14(-0.27,-0.01)$ days \\
\hline Postoperative length of stay & 0.233 & $-0.45(-0.85,-0.05)$ to $-0.08(-0.76,0.59)$ days \\
\hline Wound infection & 0.882 & $0.70(0.38,1.28)$ to $0.86(0.44,1.68)$ \\
\hline Intra-abdominal infection & 0.202 & $0.60(0.18,1.99)$ to $0.92(0.31,2.73)$ \\
\hline Pneumonia & 0.595 & $0.77(0.33,1.83)$ to $0.93(0.43,2.02)$ \\
\hline Intestinal obstruction & 0.758 & $0.58(0.21,1.63)$ to $0.86(0.30,2.41)$ \\
\hline Delayed gastric emptying & 0.053 & $1.01(0.40,2.55)$ to $1.43(0.47,4.28)$ \\
\hline Anastomosis leakage & 0.959 & $0.54(0.28,1.05)$ to $0.65(0.24,1.77)$ \\
\hline Severe complications & 0.74 & $0.55(0.37,0.82)$ to $0.87(0.52,1.46)^{\#}$ \\
\hline Overall complications & 0.229 & $0.69(0.56,0.85)$ to $0.89(0.70,1.12)^{\#}$ \\
\hline Death & 0.055 & $1.11(0.41,3.05)$ to $1.87(0.53,6.64)$ \\
\hline
\end{tabular}

\#The sensitivity analysis result is unstable. The combined result of numbers of retrieved lymph nodes became statistically significant after ignoring the research by Cui (2020) or Pugliese (2010, $p<0.05)$. The combined result of postoperative length of stay became statistically significant after ignoring the research by Cui (2020, $p<0.05)$. The combined result of postoperative length of stay became statistically non-significant after ignoring the research by Wang (2019, $p>0.05)$.

that laparoscopic D2 plus complete mesogastrium excision had lower intraoperative blood loss and a higher number of lymph nodes than conventional D2 total gastrectomy. Nevertheless, traditional laparoscopy brings some challenges to surgeons, such as limited manipulation and ergonomic discomfort. Therefore, the emergence of robotic technology can overcome most of these challenges [27]. RAGD2 technology was developed and first reported in 2002 [28]. Based on 3D vision, high magnification, and increased degrees of freedom, RAGD2 may be superior to LAGD2 [29]. Furthermore, RAGD2 would be helpful for surgeons. A recent study showed that blood loss in RAGD2 was $23.7 \mathrm{ml}$ less than that with laparoscopic or open surgery [30]. This meta-analysis showed that RAGD2 required a longer operating time, which has been reported in previous studies. RAGD2 required a longer total operative time than LAGD2 as a result of the longer docking time. However, the actual surgical time was similar between the two groups [30, 31]. Furthermore, a lower estimated blood loss in RAGD2 was previously demonstrated by Shen et al. [32]. Regarding the time to first flatus time, only two of the included studies reported a shorter time to first flatus time for RAGD2. Significant heterogeneity was also observed. Thus, performing further high-quality studies is recommend- ed. It is well known that there are many perigastric lymph nodes and blood vessels around the stomach, and the number of lymph node dissections is related to accurate pathological staging and prognosis. The performance of laparoscopic procedures can be limited by excessive intra-abdominal fat. Robotic surgery is a better tool for treating patients with thicker abdominal walls [33, 34]. For patients undergoing D2 lymphadenectomy, pancreatic damage cannot be ignored. Previous reports have suggested that specialized equipment might reduce the risk of pancreatic fistula, and Guerra et al. further demonstrated a relatively rare pancreatic complication with RAGD2 [35]. In line with previous data, we found that RAGD2 required a longer operating time and benefited from less operating blood loss, shorter time to first flatus and time to liquid diet, and fewer severe and overall complications. Thus, RAGD2 might be helpful for patients with gastric cancer.

There are some advantages in this meta-analysis. This study investigated D2 (lymphatic dissection) gastrectomy and included patients with similar basic clinical data. Furthermore, quality assessment demonstrated the high methodological quality of the enrolled studies. All outcome indicators had no significant publication bias, and the combined results were highly reliable. However, this study has some 
limitations. First, the included studies were retrospective studies, which had an inherent bias. For example, some baseline information was missing in some studies, such as tumor size, TNM stage, and ASA classification, which might affect the accuracy of the combined results. RCTs with larger sample sizes were recommended to verify the results of this meta-analysis. Second, there was a certain degree of heterogeneity among the included studies in terms of factors such as sex, age, BMI, tumor size, and TNM staging. However, these indicators lacked clear thresholds for grouping, and subgroup analysis and quantitative analysis methods were restricted to explore the potential influence on the results. Third, sensitivity analysis showed that the pooled results of the number of retrieved lymph nodes, postoperative length of stay, severe complications, and overall complications were unstable. Therefore, this conclusion should be confirmed by further studies with larger sample sizes.

\section{Conclusions}

Compared with LAGD2, RAGD2 might be a better choice for treating gastric cancers based on the lower operative blood loss, shorter time to first flatus and time to liquid diet, and fewer severe and overall complications. However, our findings need to be confirmed by more high-quality RCTs to address the obvious heterogeneity among the included studies.

\section{Acknowledgments}

Xinsheng Zhang MD and Weibin Zhang MM are co-first authors.

This study was supported by the National Natural Science Foundation of China (No. 81372669) and the Science and Technology Innovation Fund of Dalian City (No. 2018J13SN091).

\section{Conflict of interest}

The authors declare no conflict of interest.

\section{References}

1. Arnold M, Park JY, Camargo MC, et al. Is gastric cancer becoming a rare disease? A global assessment of predicted incidence trends to 2035. Gut 2020; 69: 823-9.

2. Nie Y, Wu K, Yu J, et al. A global burden of gastric cancer: the major impact of China. Expert Rev Gastroenterol Hepatol 2017; 11: 651-61.

3. Hu Y, Huang C, Sun Y, et al. Morbidity and mortality of laparoscopic versus open $\mathrm{d} 2$ distal gastrectomy for advanced gastric cancer: a randomized controlled trial. J Clin Oncol 2016; 34 : 1350-7.

4. Klein E, Shapiro R, Ben-Dahan J, et al. A prospective, randomized, three arm, open label study comparing the safety and efficacy of PP110, a novel treatment for hemorrhoids to preparation- $H(R)$ maximum strength cream in the treatment of grade 2-3 hemorrhoids. Mol Cell Ther 2015; 3: 6.

5. Buchs NC, Morel P. Three-dimensional laparoscopy: a new tool in the surgeon's armamentarium. Surg Technol Int 2013; 23: 19-22.

6. Abdelhamed MA, Abdellatif A, Touny A, et al. Laparoscopic gastrectomy with D2 lymphadenectomy for gastric cancer: initial Egyptian experience at the National Cancer Institute. J Egypt Natl Canc Inst 2020; 32: 10.

7. Lanfranco AR, Castellanos AE, Desai JP, et al. Robotic surgery: a current perspective. Ann Surg 2004; 239: 14-21.

8. Patriti A, Ceccarelli G, Bellochi R, et al. Robot-assisted laparoscopic total and partial gastric resection with D2 lymph node dissection for adenocarcinoma. Surg Endosc 2008; 22: 2753-60.

9. Lee J, Kim YM, Woo Y, et al. Robotic distal subtotal gastrectomy with D2 lymphadenectomy for gastric cancer patients with high body mass index: comparison with conventional laparoscopic distal subtotal gastrectomy with D2 lymphadenectomy. Surg Endosc 2015; 29: 3251-60.

10. Cui H, Liu GX, Deng H, et al. Comparison of short-term efficacy between robotic and 3D laparoscopic-assisted D2 radical distal gastrectomy for gastric cancer. Chin I Gastrointest Surg 2020; 23: 350-6.

11. Moher D, Liberati A, Tetzlaff J, et al. Reprint: preferred reporting items for systematic reviews and meta-analyses: the PRISMA statement. Phys Ther 2009; 89: 873-80.

12. Higgins J, Green S. Cochrane Handbook for Systematic Reviews of Interventions Version 5.1.0 The Cochrane Collaboration. Naunyn Schmiedebergs Arch Exp Pathol Pharmakol 2008; 5: S38.

13. Stang A. Critical evaluation of the Newcastle-Ottawa scale for the assessment of the quality of nonrandomized studies in meta-analyses. Eur J Epidemiol 2010; 25: 603-5.

14. Higgins JP, Thompson SG, Deeks JJ, et al. Measuring inconsistency in meta-analyses. BMJ 2003; 327: 557-60.

15. Pugliese R, Maggioni D, Sansonna F, et al. Subtotal gastrectomy with D2 dissection by minimally invasive surgery for distal adenocarcinoma of the stomach: results and 5-year survival. Surg Endosc 2010; 24: 2594-602.

16. Wang WJ, Li HT, Yu JP, et al. Severity and incidence of complications assessed by the Clavien-Dindo classification following robotic and laparoscopic gastrectomy for advanced gastric cancer: a retrospective and propensity score-matched study. Surg Endosc 2019; 33: 3341-54.

17. Ye SP, Shi J, Liu DN, et al. Robotic-assisted versus conventional laparoscopic-assisted total gastrectomy with D2 lymphadenectomy for advanced gastric cancer: short-term outcomes at a mono-institution. BMC Surg 2019; 19: 86.

18. Ye SP, Shi J, Liu DN, et al. Robotic- versus laparoscopic-assisted distal gastrectomy with D2 lymphadenectomy for advanced gastric cancer based on propensity score matching: short-term outcomes at a high-capacity center. Sci Rep 2020; 10: 6502. 
19. Hu SD, Hu ZL, Zou GJ, et al. Comparison of short-term outcome of da Vinci robotic-assisted and laparoscopic-assisted radical gastrectomy for gastric cancer. Chin J Gen Surg 2017; 30: 721-4.

20. Li SY, Song LJ, Na XB, et al. Comparison of da vinci robotic surgery system vesus laparoscopic D2 radical distal gastrectomy for gastric cancer. J Chin Pract Diagn Ther 2018; 32: 245-7.

21. Liu ZL, Zhong B, Zhao ZW, et al. A comparative study on Da Vince rbotic and laparoscopic radical gatrectomy for gastric cancer. Chin J Gen Surg 2020; 35: 100-3.

22. Shen XQ, Zhao YL, Su CY, et al. Short-term clinical efficacies of Da Vinci robotic surgical system-assisted and laparoscopy-assisted radical gastrectomy for locally advanced gastric cancer. Chin J Dig Surg 2018; 17: 581-7.

23. Xu YG, Zhang BD, Zhang J, et al. Evaluation of clinical shortterm outcomes of da vinci robotic gastrectomy for advanced gastric cancer. J Abdom Surg 2016; 29: 8-12.

24. Zhang XL, Jiang ZW, Zhao K. Comparative study on clinical efficacy of robot-assisted and laparoscopic gastrectomy for gastric cancer. Chin J Gastrointest Surg 2012; 15: 804-6.

25. Siu ICH, Li Z, Ng CSH. Latest technology in minimally invasive thoracic surgery. Ann Transl Med 2019; 7: 35.

26. Zheng CY, Dong ZY, Zheng LZ, et al. Laparoscopic D2 plus complete mesogastrium excision using the "enjoyable space" approach versus conventional D2 total gastrectomy for local advanced gastric cancer: short-term outcomes. Videosurgery Miniinv 2020; 15: 58-69.

27. Tsai SH, Liu CA, Huang KH, et al. Advances in laparoscopic and robotic gastrectomy for gastric cancer. Pathol Oncol Res 2017; 23: $13-7$.

28. Hashizume M, Shimada M, Tomikawa M, et al. Early experiences of endoscopic procedures in general surgery assisted by a computer-enhanced surgical system. Surg Endosc 2002; 16 1187-91.

29. D’Annibale A, Pende V, Pernazza G, et al. Full robotic gastrectomy with extended (D2) lymphadenectomy for gastric cancer: surgical technique and preliminary results. J Surg Res 2011; 166: e113-20.

30. Bobo Z, Xin W, Jiang L, et al. Robotic gastrectomy versus laparoscopic gastrectomy for gastric cancer: meta-analysis and trial sequential analysis of prospective observational studies. Surg Endosc 2019; 33: 1033-48.

31. Wei Y, Yu D, Li Y, et al. Laparoscopic versus open gastrectomy for advanced gastric cancer: a meta-analysis based on high-quality retrospective studies and clinical randomized trials. Clin Res Hepatol Gastroenterol 2018; 42: 577-90.

32. Shen WS, Xi HQ, Chen L, et al. A meta-analysis of robotic versus laparoscopic gastrectomy for gastric cancer. Surg Endosc 2014; 28: 2795-802.

33. Gallo T, Kashani S, Patel DA, et al. Robotic-assisted laparoscopic hysterectomy: outcomes in obese and morbidly obese patients. JSLS 2012; 16: 421-7.

34. Markar SR, Karthikesalingam AP, Venkat-Ramen V, et al. Robotic vs. laparoscopic Roux-en-Y gastric bypass in morbidly obese patients: systematic review and pooled analysis. Int J Med Robot 2011; 7: 393-400
35. Guerra F, Giuliani G, Formisano G, et al. Pancreatic complications after conventional laparoscopic radical gastrectomy versus robotic radical gastrectomy: systematic review and meta-analysis. J Laparoendosc Adv Surg Tech A 2018; 28: 1207-15.

Received: 31.12.2020, accepted: 15.03.2021. 